\title{
A WRONG TURN IN LEGAL THEORY?*
}

\author{
Brian BURGE-HENDRIX ${ }^{1}$
}

Resumen:

¿Acaso una comprensión apropiada del papel del quehacer filosófico y su relación con la investigación científica implica que deberíamos reemplazar el análisis conceptual por alguna otra metodología? Brian Leiter responde que sí al ofrecer una crítica metodológica a la filosofía del derecho analítica reciente. El autor sostiene que la propuesta de Leiter para destrabar el debate Hart/Raz, consistente en apoyar una versión excluyente de la regla de reconocimiento sobre la base de su utilidad socio-científica, nos dirige hacia una concepción sumamente estrecha de las características relevantes de un sistema jurídico.

\begin{abstract}
:
Does a proper understanding of the role of philosophical inquiry and its relation to scientific inquiry entail that we should replace conceptual analysis with another methodology? Brian Leiter supports that conclusion by offering a methodological criticism of recent analytical legal philosophy. I argue that Leiter's proposal for breaking the deadlock of the Hart/Raz debate by supporting an exclusivist account of the rule of recognition on the grounds of its social-scientific utility leads to an unduly narrow conception of the relevant features of a legal system.

* Este artículo aparecerá como capítulo 6 del libro Epistemic Uncertainty and Legal Theory, mismo que será publicado por Ashgate Publishing.

1 For comments and discussion of earlier versions of this work, I thank Renato Cristi, Imer Flores, Violetta Igneski, Matt Kramer, Phil Soper, Wilrid Waluchow, the participants at my seminar presentation at the Legal Research Institute at the National Autonomous University of Mexico, and the members of the Cambridge Forum for Legal and Political Philosophy. I also wish to acknowledge the Social Sciences and Humanities Research Council of Canada for its generous financial assistance, Churchill College for providing a congenial research and living environment, and the Law Faculty of Cambridge University.
\end{abstract}


Summary: I. Descriptive Explanations and Explanatory Concepts. II. The Argument Against Conceptual Analysis. III. Ordinary Language Philosophy and Intuitions. IV. Methodological Minimalism. V. Conceptualizing "The Constitution". VI. Levels of Analysis. VII. The Aim of Analysis. VIII. Restrictive Methodologies. IX. An Interim Reply to Leiter. X. The Division of Labour Argument. XI. Methodology and Convenience. XII. Written and Unwritten Rules. XIII. Participant Perspectives.

\section{DESCRIPTIVE EXPLANATIONS AND EXPLANATORY CONCEPTS}

Brian Leiter takes the central and seemingly intractable dispute within legal positivism known as the Hart/Raz Debate, a debate about "the correct account of the content of the rule of recognition and its relationships to the possibility of law's authority", ${ }^{2}$ as proof that the prevailing norms of theory choice and development applied by positivist jurisprudents are insufficient. Not only are there competing positivist conceptions (of law, of legal authority, of the rule of recognition), but also and more importantly these conceptions are irreconcilable insofar as "the differing conceptual claims are in tension such that no one theory can account for the viable concepts". ${ }^{3}$

An often overlooked factor in the development of this seemingly intractable dispute is a central methodological commitment of positivist jurisprudence. In developing a philosophical account of law, one cannot pick and choose between key concepts so as to parcel them together without regard for their mutual implications. This is so because particular concepts and accounts of key features of legal systems may implicate or preclude other concepts and ac-

2 Leiter, Brian, Naturalizing Jurisprudence, Oxford, Great Britain, Oxford University Press, 2007, p. 154. The Hart/Raz debate is the dispute between Inclusive Legal Positivists and Exclusive Legal Positivists, to use Wilfrid Waluchow's terminology, or Soft and Hard positivists, to use H. L. A. Hart's phrasing.

3 Ibidem, p. 133. 
counts. One cannot, for instance, choose between the best theoretical accounts of authority and the Rule of Recognition as if they have no relation to each other, for the particular conceptions deployed in a positivist account of law, such as a conception of legal authority and of possible criteria for legal validity, must work together in the theory as a whole. Moreover, they must do so because in actuality notions of legal authority and criteria for legal validity must be compatible if legal systems are to avoid a crippling state of obvious incoherence. The reciprocal relation between theoretical concepts and their practically applied counterparts can be usefully termed descriptive/conceptual reciprocity.

Modern legal positivists aim to elucidate the systematic character of legal systems, the tasks and terms of legal practice, and the relation of law to its subjects and administrators as well as their beliefs about and attitudes towards their legal system. The goal is to understand the pre-theoretical data - the social phenomena of institutions we generally and often unreflectively refer to as legal systems - in light of common characteristics rather than contingent particularities. The hoped-for product of the work of most legal positivists, then, is a descriptive explanation of actual legal systems. ${ }^{4}$

A descriptive-explanatory account of legal systems deploys a abstract, hence manageable, presentation of the common features of systems of law in which those features are elucidated as inter-related elements of a complex system rather than merely as an aggregate of characteristics. Some of these elements are amenable to empirical observation, such as the existence of a system of courts, while others, which are inherently more contestable from the theoretical point of view, are deduced or inferred, such as Joseph Raz's service conception of authority. Yet other elements are presented in the form of theoretical concepts

4 For a discussion of the nature and aims of descriptive-explanatory legal theories, see Wilfrid Waluchow, Inclusive Legal Positivism, Oxford, Great Britain, Oxford University Press, 1994, pp. 40 and 41. 
which draw-together characteristics of legal systems that are not always explicitly recognized by its participants.

These hermeneutic overlays are explanatory concepts. An exemplar of such a concept is Hart's Rule of Recognition, which, by identifying a particular type of "social rule", explains how determinations of legal validity in a particular legal system avoid an infinite regress. The Rule of Recognition is an abstract presentation of a kind of practical social rule that (explicitly or implicitly) forms part of every legal system's institutional practices. Explanatory concepts are essential components of any descriptive legal theory. As Hart described them, these concepts "focus attention on elements in terms of which a variety of legal institutions and legal practices may be illuminatingly analyzed and answers may be given to questions, concerning the general nature of law, which reflection on these institutions and practices has prompted". ${ }^{5}$ When properly deployed explanatory concepts have a basis (though not necessarily an explicit one) in actual legal systems. ${ }^{6}$

However, the correct way to choose, employ, and develop explanatory concepts in legal philosophy has become increasingly controversial. The Hart/Raz debate persists because positivists in both camps offer competing explanatory concepts (e. g. of legal authority and of the Rule of Recognition) which work within each of their theoretical accounts as a whole, and align reasonably well with the data given by actual legal practices, and yet these explanatory concepts contradict each other. Characterizing the desired result of the principle of descriptive/conceptual reciprocity is key to understanding the epistemic uncertainty in which the debate is mired, for the choice of concepts is driven by norms

5 Hart, H. L. A., The Concept of Law, 2nd. ed., Oxford, Great Britain, Clarendon Press, 1994, p. 240.

6 This does not mean, however, that a particular explanatory concept is actually used by participants in any or every legal system. The Rule of Recognition, for instance, is not explicitly mentioned in Justinian's Digest, but the Rule of Recognition qua explanatory concept is applicable to and can indeed enhance our understanding of the Ancient Roman legal system. 
of theory choice and development upon which all positivists in principle agree. Leiter offers a solution to the problem of epistemic uncertainty, a solution that depends on our applying a new criterion for theory choice and development.

\title{
II. The Argument Against Conceptual Analysis
}

Leiter advocates a form of replacement naturalism whereby "philosophical questions about the relationship between evidence and theory... [are] replaced by purely empirical, scientific questions about the causal relations between the two relata". ${ }^{7}$ Philosophers of law, he argues, have abdicated their responsibility to keep up with current methodological practice:

\begin{abstract}
Almost all of philosophy has succumbed - or at least felt the need to respond - to this naturalistic turn. One of the striking holdouts from the naturalistic turn, however, has been none other than legal philosophy, which proceeds via conceptual analysis and intuition-pumping as though nothing had transpired in philosophy in the last forty years. ${ }^{8}$
\end{abstract}

Why, however, should we replace philosophical questions regarding evidence and theory with some other mode of inquiry, and why should we think that this approach will dispense with the uncertainty at the core of contemporary positivist debates about key features of law? The grounds for accepting Leiter's replacement strategy cannot simply be that it reflects "the methodological Weltanschaung of philosophy in our time", 9 but rather must rest on a demonstration that philosophical inquiry into theory and knowledge - the project of epistemology itself - has arrived at some

7 Leiter, Brian, "The Naturalistic Turn in Legal Philosophy", American Philosophical Association Newsletter on Law and Philosophy, vol. 00 no. 2, 2001, URL: http://www.apa.udel.edu/apa/publications/newsletters/v00n2/law/06.asp, pp. $142-146$.

8 Idem.

9 Idem. 
new insight into appropriate norms of theory construction such that conceptual analysis is incompatible with those norms. Leiter's argument to that end goes as follows:

1) Non-naturalistic legal philosophers, e.g. legal positivists, are unable to conclusively explain or even describe several important features of law, e.g. the nature of legal authority.

2) The best descriptive-explanatory accounts of these features of law rely on explanatory concepts whose veracity, in turn, relies on the strength of conceptual arguments.

3) The conclusions of conceptual analysis are always insecure because:

a) They rely on our intuitions, which are notoriously fickle.

b) They are revisable in light of empirical evidence, and so are ever mutable in light of future knowledge.

4) Therefore, conceptual analysis is an inadequate methodology for describing and explaining law.

This argument is offered both in support the rejection of conceptual analysis and to prefigure the need for a new meta-theoretical-evaluative criterion: "facilitating successful a posteriori theories". ${ }^{10}$ Later in this essay we shall consider the new evaluative criterion. At this juncture, however, I want to show that in many respects Leiter offers a caricature of conceptual analysis, at least with regard to its use as the standard methodology of legal positivism.

\section{ORDinARY LANGUAGE PHILOSOPHY AND INTUITIONS}

In the face of disparate explanatory concepts of the key features of legal systems, it is not unreasonable to question the theoretical fruitfulness of a methodological approach whereby contradictory explanatory concepts are offered by 
different descriptive-explanatory legal theorists, as is the case in the Hart/Raz Debate. Leiter avows a naturalistic methodology as the cure for the methodological difficulties engendered by the inter-relation of explanatory concepts within a philosophical account of law. The naturalistic methodology is purportedly superior in part because it eschews appeals to intuition. In what follows, I show that that it is not the case that descriptive-explanatory legal theorists rely on intuitive appeal to support their explanatory concepts, although intuitions do play a minor but important role in the work of some positivists.

According to Leiter, positivists suffer from having made "the linguistic turn":

In its contemporary form, linguistic-turn philosophers typically examine some concept ("justice" or "law" or "mind"), looking at how we use language to express the concept as a way of clarifying our intuitions about its content. How we talk and how we intuit dominate the methodological armory of the linguistic-turn philosophers. ${ }^{11}$

The force of Leiter's critique of "linguistic-turn philosophers" does not rely on whether speech can express concepts, nor whether the analysis of speech is the best way to explain concepts or things conceptual, nor even whether all descriptive jurisprudents are concerned with law-talk at the object-level (i. e., the realm of actual legal practices). Leiter himself does not dispute the first point, and with regard to the second, he is skeptical yet not entirely dismissive. Furthermore, at least one analytical legal philosopher, namely Joseph Raz, has little to say about how we use words and much to say about the nature of practical reason. What Leiter must establish is the claim that positivist legal theorists rely on intuitions about explanatory concepts as evidence of their veracity. 
Consider H. L. A. Hart's legal theory. It is true that Hart was influenced by ordinary language philosophy, 12 and that he "famously endorsed J. L. Austin's view",13 which holds that by examining ordinary language we are "using a sharpened awareness of words to sharpen our perception of phenomena". ${ }^{14}$ But does this concern with language support Leiter's claim that positivists are "intuition-pumping" and that they believe that explanatory concepts are proved or disproved by our intuitions regarding it?

The first thing to note is that Hart, though himself influenced by ordinary-language philosophy, did not present a legal theory which relied upon it. For example, on p. 103 of the 2nd. edition of The Concept of Law, Hart discusses legal validity as a concept whose usual use, $i$. $e$. "This law is invalid", presupposes the context of a particular legal system and its rules; he then draws an analogy with the game of cricket as the context whereby the statement "He is out" presupposes the rules of cricket. One need not have any intuitions regarding cricket to see that Hart's example elucidates the contextual character of statements of legal validity, hence the contextual character of concepts of legal validity.

Even where Hart employs counterfactual situations and purely hypothetical statements regarding those situations, he certainly does not appeal to our intuitions in order to define the content of a concept. For instance:

Let us recall the gunman situation. A orders B to hand over his money and threatens to shoot him if he does not comply.

12 Whether ordinary language philosophy is something upon which Hart's theory of law depends is contestable. Yasitomo Morigiwa, for instance, argues Hart's legal theory tacitly relies on an incorrect theory of language, but he does not argue that Hart is an ordinary language philosopher. See Morigiwa, Yasitomo, "The Semantic Sting in Jurisprudence: Hart's Theories of Language and Law", Archive für Rechts- und Sozialphilosophie, vol. 40, 1991, pp. 21-30.

13 Leiter, Brian, op. cit., n. 7.

14 Idem. Leiter cites Hart (p. 14 of The Concept of Law (2nd ed.), who is himself citing John Austin (Austin, John, "A Plea for Excuses", Proceedings of the Aristotelean Society, vol. 57, 1956-57, pp. 123-32. 
According to the theory of coercive orders this situation illustrates the notion of obligation or duty in general. ... The plausibility of the claim that the gunman situation displays the meaning of obligation lies in the fact that it is certainly one in which we would say that $B$, if he obeyed, was "obliged" to hand over his money. It is, however, equally certain that we should misdescribe the situation if we said, on these facts, that B "had an obligation" or a "duty" to hand over the money. So from the start it is clear that we need something else for an understanding of the idea of obligation. ${ }^{15}$

In what sense is Hart "intuition-pumping" here? His hypothetical example suggests that the concept of obligation referred to by obligation-talk admits of fine distinctions, and that one of these distinctions -being subject to pure coercive force- is dissimilar from the others. We do in fact think it odd to conflate the meaning of a statement about the exertion of coercive force $(e . g$. ., "Since he had a loaded pistol pointed at his head, he was obliged to give the gunman the money") with the meaning of a statement about, say, proper behavior towards one's mother (e. g., "Since she is his mother and is ill in hospital, he has an obligation to visit her"). But nothing in this suggests that the question of what a legal obligation is, and of what coercive force can oblige us to do, can or ought to be settled by appealing to our intuitions.

Leiter's error is to conflate so-called intuition-pumping with the long-standing and useful technique of marking a counter-intuitive claim or feature of something as a sign that further investigation is in order. Imagine someone remarking, "Canadians have no effective legal recourse should their properly made and registered vote, or even the votes of all voting Canadians as a whole, be ignored by Parliament". That statement is remarkably anti-intuitive, for how can we reconcile such a claim with our knowledge that Canada is considered to be a parliamentary democracy under the rule

15 Hart, H. L. A., op. cit., n. 5, p. 82. 
of law? Yet that statement is also almost certainly a true proposition regarding the actual state of Canadian law -or so thinks the Supreme Court of Canada- for it happens to be the case that a Canadian's legal right to vote is in fact legally unenforceable. ${ }^{16}$ Thus the counter-intuitiveness of the statement suggests a possible divergence between the Supreme Court's concept of a right to vote and that of the ordinary Canadian. Since voting is a social practice with some significance, and since the Supreme Court's statements carry considerable force, here we have the basis for a fruitful investigation into the complexity Canadian socialpolitical practices. But that investigation, should we undertake it, does not require us to refer to anyone's intuitions; it certainly doesn't require that we define the concept of a right to vote according to our intuitions as legal theorists; and we may even arrive at theoretical conclusions which are "intuitively unsound" despite being true.

Leiter does helpfully highlight the problem of uncertainty as regards the best descriptive-explanatory accounts of fundamental features of legal systems, an uncertainty which accounts for the remarkable persistence of the Hart/Raz debate. Positivist legal theorists dispute the available explanatory concepts for several key features of juridical law, and standard meta-theoretical-evaluative criteria and methodological principles do not appear to have resolved these disputes. ${ }^{17}$

16 It is a constitutional convention which ensures that, should Canadians vote a government out of parliament, that government will relinquish power. But the very definition of a constitutional convention is that it is unenforceable by the courts. According to its Supreme Court, the constitutional conventions of Canada present a "striking peculiarity" insofar as they are not "in the nature of statutory commands which it is the function and duty of the courts to obey and enforce" (Reference Re Resolution to Amend the Constitution of Canada [1981] 1 SCR 753 at 754.

17 A meta-theoretical-evaluative criterion is an evaluative yet non-moral norm used to judge the merit of a theory (e.g., simplicity, coherence, explanatory power). See Waluchow, Wilfrid, op. cit., n. 4, p. 20. The same idea has also been elucidated by others using different labels. See Coleman, Jules, The Practice of Principle, Oxford, Great Britain, Clarendon Press, 2001, p. 95; Dickson, Julie, Evaluation and Legal Theory, Oxford, Great Britain, Hart Publishing, 2001, p. 178; Perry, Stephen, "Hart's Methodological Positivism", Hart's Postscript, edited by Jules Coleman, Ox- 
As a critique of the standard method as employed in legal theory, however, Leiter's polemic against so-called linguistic-turn philosophers is misguided. Indeed, Joseph Raz argues that "so long as in one's deliberation about the nature of law and its central institutions one uses language without mistake, there is little that philosophy of language can do to advance one's understanding". ${ }^{18}$ Accusations of intuition-pumping falsely suggest that descriptive-explanatory legal theorists defend their theoretical conclusions on the grounds that they are "intuitively correct". Leiter's falsifying polemic is best understood as intended to provoke interest in Leiter's own legal-theoretical methodology, a methodology that aims to avoid the uncertainty surrounding key features of legal systems as they are understood by contemporary legal positivists.

In summary, let us recount four of the weaknesses in Leiter's overall position regarding proper legal-theoretical inquiry. First, I have already pointed out that positivist legal theorists do not claim that intuitive appeal is either (i) a good reason in itself for accepting or rejecting an explanatory concept, or (ii) the goal of a good descriptive-explanatory account of law. Second, in the case of positivist legal theory, Leiter's account of the so-called "linguistic turn" in philosophical inquiry is more polemical than substantive. Descriptive-explanatory legal theorists do not attempt to determine the content of their explanatory concepts by means of ordinary language philosophy. Third, all positivists actually support 3.2 supra. Since the phenomenon of law does not uncontroversially appear "as it is", a meta-theoretical evaluation of several legal theories will normally be unable to fully separate the value of their substantive conclusions from the value of their theoretical methodology.

ford, Great Britain, 2001, pp. 313 and 314; Sumners, Robert, "Notes on Criticism in Legal Philosophy", More Essays in Legal Philosophy, edited by Robert Sumners, Berkeley and Los Angeles, University of California Press, 1971, p. 10. Leiter himself uses the term "epistemic norms"; see Leiter, Brian, op. cit., n. 2, p. 50.

18 Raz, Joseph, "Two Views on the Nature of the Theory of Law", Hart's Postscript, Ed. Jules Coleman, Oxford, Great Britain, 2001, p. 6. 
This difficulty is even more pronounced when we consider a particular legal theory's conceptual claims, since concepts are even less amenable to simple observation. Thus it is the case that most every substantive conclusion may be challenged on methodological (or other meta-theoretical) grounds, and most every methodology (or other meta-theoretical commitment) may be challenged on the basis of its substantive conclusions. ${ }^{19}$ Not only do positivists agree with Leiter on the methodological principle of descriptive/conceptual reciprocity - that is, to so far as possible to relate explanatory concepts to the observable characteristics of actual legal systems - they also take that principle as a reason to avoid a priori restrictions on the explanatory concepts used in their legal theory. The fact that a positivist account of law is revisable in light of future inquiry is $a$ good feature of that type of legal theory, and no positivist says otherwise.

\section{Methodological Minimalism}

Although Leiter defines conceptual analysis in very general terms, ${ }^{20}$ let us focus solely on the minimalist methodology of legal positivism. Put roughly and for the sake of contrast, we might say that legal positivists examine particular legal systems in order to discover and explicate juridical law as a concept. In other words, positivists try to glean conceptual truths from legal phenomena. What we might think of as a converse approach works in the opposite di-

19 These are deep waters indeed and it is not my aim in this essay to explicate the relation between the standard method and revisions due to empirical observation. It is enough at this juncture to point out that positivists are aware of the frailty of that relation and the need to keep it in mind.

20 Kant's transcendental account of the necessary categories of human experience is supposedly an example of conceptual analysis. Since physics has shown that non-Euclidian geometries are consistent with the nature of space and time, Kant's a priori account of how the world must be for us is therefore disproved. Leiter takes note of a number of other examples, including the law of excluded middle, as examples of failed a priori analyses intended to secure absolute truths. See Leiter, Brian, op. cit., n. 7. 
rection: it examines legal systems by means of an already determined concept of law which is explicitly constrained or conditioned by a priori requirements of morality, history, or metaphysics. Non-minimalist legal theorists include Plato, whose thoughts on law are closely tied to his metaphysics, such that the status of a legal edict is necessarily connected to an overarching Idea of justice; Cicero, whose studies of law exhibit an inextricable dependence on a theory of nature, particularly human nature, and of nature's imposition of certain requirements on any existent and enduring legal system; and Kant and Hegel, whose forays into legal theory make extensive use of their own versions of philosophical anthropology; and so forth. By taking a view of law which rejects, for instance, an a priori moral restriction on the content of purported laws, legal positivists advocate a minimalist methodology for legal theory-an approach to law as an object of theoretical explanation where that object is, so far as possible, understood on its own terms. ${ }^{21}$

There is an important subtlety here, one which we can elucidate with a distinction. Henceforth, let us call any actual legal system or the set of all actual legal systems the explanandum: the actual phenomenon (or set of phenomena) we aim to describe and explain. To begin to develop a theoretical explanation of that explanandum, however, we must "filter" the immense amount of pre-theoretical data the explanandum comprises. We are not, for instance, concerned with whether judicial decisions are handwritten or typewritten, or with the cut and colour of judges' robes. While the explanandum comprises all legal systems and their features, our explanatory object is the generalized or filtered set of data with which we work. Legal positivism is

21 This rough description is somewhat misleading, however, since positivists do employ conceptual arguments in order to re-categorize the data which forms their object of explanation. Raz and other exclusive positivists suggest that the conceptual necessity of legal systems having to claim legitimate authority contradicts the apparent "fact" that principles of morality can serve as criteria of legal validity. 
minimalist in that it refrains from imposing a priori constraints on that object.

We shall briefly consider the initial stages of giving a theoretical description and explanation of a particular phenomenon - the constitution of Canada - from the perspective of a minimalist investigator who aims to get a rough idea of the essential features of that phenomenon. This tentative perspective is not that of a legal theorist or moral activist. It is, in a very approximate way, the perspective of Hart's external observer, but in this case the external observer is particularly ignorant of the phenomenon being investigated. The investigator has no classificatory schema to demarcate legal rules from moral rules, nor legal institutions from political institutions, and so forth. We shall not develop a thoroughgoing analysis of Canadian constitutional practices, legal or moral or political. Our goal is to identify some of the virtues of methodological minimalism and to see why those features are laudable.

\section{Conceptualizing "The Constitution”}

Nation-states are political entities comprising a number of institutions and social practices. Canada is a nation-state with a typical assortment of modern institutions and enduring political practices. Most all Canadians consider the Charter of Rights and Freedoms to be an important and influential feature of Canadian society. They also consider the Charter to be part of Canada's constitution. What, we might ask, is this "constitution"?

If we want to understand the Charter and its role (or, if most Canadians are mistaken, its not having a role) in Canada's constitution, then we need a conception of "constitution" in order to begin our analysis. Since we do not know whether Canadians have a correct account of what a constitution is, we might reasonably turn towards experts in sociology or political science who have developed empirically-tested concepts of things like constitutions. There are 
political-theoretical accounts according to which constitutions are simply the form or institutional arrangement of political institutions, where "political institution" is broadly construed so as to include such empirically observable things as legislatures and courts. This notion of a constitution is well-suited to what Leiter calls a posteriori studies insofar as it specifies constitution-types according to observable characteristics, e. g. democratic parliaments, juntas, monarchs, and so forth. Let us call this conception C-Pol.

A political theory which uses $C$-Pol and the type of legal theory which we have been calling descriptive-explanatory both share a methodology: they attempt to identify institutional structures and practices in order to develop general explanations of them. The descriptive-explanatory political theorist, for example, notes that according to C-Pol there are $\mathrm{X}$ number of constitutional-types, such as democracies, oligarchies, etc. The descriptive-explanatory legal theorist analogously notes that according to the best available conception of law - we shall call it C-Law- there are Y number of rule-types, such as primary and secondary rules.

Could we make use of the political theorist's conception of the Canadian constitution - that is, the particular constitution-type Canada has in light of $\mathrm{C}$-Pol- as a starting point for understanding the relationship between the Charter and Canada's constitution? Unfortunately, we cannot. $C$-Pol excludes the possibility that the Charter is part of Canada's constitution. According to that conception, the Charter could affect Canada's constitution by influencing the formal arrangement of political structures, but it could not be properly said to be a part of the constitution because a constitution is merely an abstract theoretical entity. C-Pol exists only because political theorists posit its existence, regardless of the fact that $\mathrm{C}$-Pol is intended to be a descriptive claim about the actual nature of real nation-states. ${ }^{22}$

22 In other words, the political theorist is using her conception of what a constitution is to explain the object-level instance of the Canadian legal system. She is 
If we want to describe and explain the Charter's role in Canada's constitution, or at least describe and explain why and how Canadians mistakenly believe that it does play a role, then it is pointless to begin with an account of "constitution" which determines a priori that the Charter and Canada's constitution are necessarily distinct. We aim to describe and explain things as they are, and it is clear that Canadians often speak of the Charter as if it were a part of Canada's constitution. Even the judges on Canada's highest court do so. C-Pol is unhelpful insofar as it implies that we ought to reject $a b$ initio the claims and self-reports of even Canada's Supreme Court. What ought we, as descriptive-explanatory Charter theorists, to do?

We could simply reject that implication of $C$-Pol by distinguishing between the political-theoretical sense of the term "constitution" and the various senses of the term used by contemporary Canadians. We would, in that case, note that the political-theoretical term is what Stephen Perry calls "a term of art" and accept it as appropriate in one context but not another. This is not an acceptable solution, however. In fact, it points to a much deeper problem than careful use of theoretical terminology. The real issue is not whether it would be more convenient for theorists to use the same words as the participants in the practices being studied. The real problem for us is that the political theorist's term refers to a different referential object than that referred to (in most instances) by contemporary Canadian constitutional practices.

\section{LEVELS OF ANALYSIS}

It might be objected that all this talk of $C$-Pol amounts to terminological quibbling or, even worse, a category error. Why not say that $\mathrm{C}$-Pol, being an abstract theoretical entity, need not correlate with Canadian social and political prac- 
tices at all? We know that such practices prima facie exist; if $C$-Pol denies that fact, so much the worse for $C$-Pol. A category-error account might suggest that what its Supreme Court says of Canada's constitution may be true even though it contradicts $\mathrm{C}$-Pol since we are really talking about two different types of creature: Canada's constitution is (somehow) a concrete existing thing while $\mathrm{C}$-Pol is merely an abstract theoretical entity. On this account, the claim that $\mathrm{C}$-Pol involves Canadians in conceptual incoherence is just the result of confusing the meta-level of political theory with the object-level of Canadian legal and political practices. ${ }^{23}$ In fact, however, the meta-level/object-level distinction does not map onto the distinction between "abstract" theoretical inquiry and concrete social practices. A Canadian judge who refers to the Charter as part of Canada's constitution is already working with an abstract conception. While that judge's conception - let us call it C-Judgeis not so general as to render irrelevant everything but the formal arrangement of political institutions, it is nonetheless just as much a "mere theoretical entity" as C-Pol. Judge X's determinations of Canadian law are propositions regarding an actual referential object shared by other Canadian judges. If we have made a category error, it is not one which confuses "real" things with "merely theoretical" things.

More importantly, if C-Judge exists at the object-level of Canadian legal practices by virtue of its application or elaboration by Judge $\mathrm{X}$ and his compatriots, then it appears that the object-level with which legal theorists are concerned already contains conceptions like C-Judge. This raises the issue of whether $C$-Pol in some sense needs to account for C-Judge. A theory which determines a priori that Canadian Supreme Court Justice Binnie's conception of Canada's constitution is utterly mistaken is prima facie a

23 To paraphrase Gilbert Ryle's example, we might say that Canadian constitution-talk refers to something like a college building, while the political theorist's term of art refers to something like a university. 
poor account of Canada's constitution. ${ }^{24}$ There is little point in giving a descriptive-explanatory account of the Charter if we decide, a priori and according to $\mathrm{C}$-Pol, that Canada's Supreme Court is conceptually confused. ${ }^{25}$ It might seem that to remedy the contradiction between $\mathrm{C}-\mathrm{Pol}$ and $C$-Judge we must take $\mathrm{C}-\mathrm{Pol}$ as an abstract theoretical entity while accepting C-Judge as some other type of object. We would then be faced with having to relate the former to the latter - that is, we would need to develop a theory of how $\mathrm{C}$-Pol can accurately reflect something else entirely, namely C-Judge. But this seems to be an actual instance of the kind of "ontological promiscuity" which Leiter wants to avoid, and which we also ought to avoid so long as we advocate a minimalist descriptive-explanatory methodology. Fortunately, we can sidestep the entire ontological debate with a methodological postulate:

M1 - There are different conceptions of social practices and institutions such that, so long as the conceptions are elaborated at the object-level by actual social practices, those conceptions can be the referent of a meta-level descriptive claim.

Three important clarifications are in order. First, it is possible to reduce the notion of a social institution to that of a social practice. We need not do so, but knowing that we can may comfort someone who is unsettled by the notion that a institution can be said to actually do something. (While we may also reduce social practices to observable patterns of behaviour, a reduction of this sort is largely unhelpful as to the meaning and role of conceptions like C-Judge.) Secondly, it is important to keep in mind that $M 1$ is a methodological postulate rather than an ontological

24 As Raz observes, "we know well that if some theory of law yields the result that American law is not law, it is a misguided theory of law" (Raz, Joseph, op. cit., n. 18 , p. 35).

25 This is not to say that after due reflection and inquiry we might not decide that, in fact, Canada's Supreme Court is conceptually confused. That is an open question. What we need to avoid is predetermining an answer to that question on unreasonable grounds. 
claim. It does not entail, for instance, that ideas exist if and only if they are spoken of. Rather, a conception such as $C$-Judge can be said to exist insofar as we observe that Judge X says something to the effect of C-Judge. Note that we can also make the same claim with regard to C-Pol: it exists insofar as we observe that some political theorist says something to the effect of C-Pol. C-Pol and C-Judge may have other modalities of existence, of course. It is enough for our purposes to make the minimum necessary ontological commitment. Thirdly, M1 is deliberately vague. We have not yet specified what it is for a social practice to "elaborate" an idea. For now, it is enough to note that if Judge $\mathrm{X}$ says something to the effect of C-Judge in the courtroom, then $C$-Judge can be said to exist in at least that context. It is important to note that the meta-level descriptive claims allowed by M1 may take other meta-level descriptive claims as referents. In other words, the descriptive claim "Aristotle states $\mathrm{C}$-Pol" is a meta-level descriptive claim about what is itself a meta-level descriptive claim; we can consider $\mathrm{C}$-Pol as an object-level feature of the practice of political theory even though, from Aristotle's perspective, $\mathrm{C}$ - $\mathrm{Pol}$ is a meta-level claim about regular political practices. ${ }^{26}$

When considering a particular meta-level descriptive claim there is much potential for confusion about the object-level and the meta-level. This is so because it is the perspective of the theorist which constitutes the meta-level, regardless of the claim under consideration. Hence our second methodological postulate:

26 And this is why it is always possible to point out that a supposedly neutral theoretical claim or theoretical methodology implicates a non-neutral context. For example, the methodological claim "One can describe law without praising or condemning it" can be the subject of another claim such as "To hold that "One can describe law without praising or condemning it" implies that law admits of moral predicates". The latter claim may, for instance, appear as part of an argument suggesting that it is more important to attribute the correct moral predicates to law than merely to describe it, and so anyone who engages in only the latter suffers from a kind of willful moral blindness, and so forth. 
M2 - The object-level is both relative to and dependent on a theoretical perspective.

This is a subtle but very important point. Positivists, for instance, are very concerned to describe law as it is and to correlate their conceptual claims with descriptive claims whenever possible. Accordingly, when positivists talk about law, the discussion often refers to only two levels of analysis: the object-level of actual legal systems and the meta-level where those systems are discussed generally and in abstraction from any particular legal system-there are legal systems and there is the concept of law. Even the most empirically-minded positivist, however, recognizes that actual legal practices involve participants who use concepts like C-Judge. These are also meta-level concepts, though they tend to be more practical than theoretical. For the sake of having a useful label with which to distinguish them from our legal-theoretical conceptions, let us call these "practical" or "participant-level" concepts.

Consider again the familiar legal theory of H. L. A. Hart. Hart aimed to elaborate a general concept of law in light of these practical legal concepts, and to see how they were used in similar or different ways from moral concepts. Hart would, therefore, accept M1 as a useful constraint on positivist legal theory. His own work clearly deals with concepts as they are used in actual legal systems, e.g. the concept of a legal duty, but he aims to describe them rather than to discipline or "engineer" their use. ${ }^{27}$ Hart's meta-level claims about the nature of a legal duty are based upon the practical conceptions of legal duty already at work within actual social practices. Insofar as Hart describes and explains the conceptions already at work within legal systems, he (and any other descriptive-explanatory legal theorist) must also accept M2. The Hartian account of law describes conceptions like $C$-Judge, yet C-Judge is itself a meta-level descrip-

27 I take the pejorative label of "engineering" from Jules Coleman, who refers to Liam Murphy's quasi-positivist methodology as a means for "engineering" or "legislating" the concept of law. See Coleman, Jules, op. cit., n. 17, p. 208. 
tive claim, $i$. e., the type of claim Judge $X$ might make regarding the law of Canada. Hart's concern was not to prove whether C-Judge was epistemically correct or not, either as a matter of morality or as a matter of practical legal propositions about Canadian law. Rather, Hart's aim was to describe and explain participant-level conceptions like $C$-Judge in modern municipal legal systems, and then to show that a general account of law could be given such that juridical law could be explained in light of its central features.

\section{The Aim of ANALYSIS}

Whatever an actual legal system might be in practice, the description and explanation of it is theoretical, as is the thing being described and explained-the explanatory object. When our theoretical conceptions of our shared explanatory object cannot be reconciled with the concept of it -in other words, when our descriptions and explanations would, taken as a whole, suggest an actual contradiction in our explanatory object itself- we find ourselves in a state of theoretical uncertainty. We can also be uncertain about the veracity of participant-level conceptions: we may be unsure, for instance, as to whether Judge X's conception C-Judge is correct in relation to Canadian law. Thus theoretical uncertainty may be more than a simple conflict between conceptions at the same level of analysis. Accounting for our legal-theoretical uncertainty is difficult in large part because uncertainty about a claim at one level can arise in light of further uncertainty about a claim at another level. For example, the participant-level conception C-Judge ("Canada's constitution includes the Charter") and the meta-level conception C-Pol ("Bills of rights cannot be 'part' of a constitution, properly understood") are not obviously reconcilable in a unitary account of the constitution. Thus we are uncertain whether the meta-level conception $\mathrm{C}$-Pol is appropriate given the participant-level conception C-Judge; likewise, we do not know whether the participant-level conception C-Judge is necessarily mistaken, since it is possible 
that the meta-level conception $\mathrm{C}$-Pol is true. Unless we resort to a priori suppositions, any attempt to describe and explain a complex social phenomena will involve epistemic uncertainty at many levels.

What, then, makes a particular conception of Canada's constitution good or bad? Can it be the truth of the conception? Since our aim is to develop a descriptive-explanatory account of the relation between Canada's Charter and its constitution, the worth of a conception of the constitution is relative to that aim. Yet we should not assume that our commitment to descriptive accuracy and other epistemic norms entails that for us the epistemic certainty of a conception is of paramount importance. This is immediately obvious once we consider an important difference between the participant-level conception C-Judge and the meta-level conception $\mathrm{C}$-Pol. From the meta-theoretical perspective, it is possible for a conception to take on three different roles: it may be a product, an instrument, or a feature. That is, a conception may be:

(1) The result of a theoretical inquiry, e. g. C-Law.

(2) Used to filter the pre-theoretical data, e. g. C-Pol.

(3) A feature of our explanatory object, e. g. C-Judge.

Different theoretical approaches to law may purposely limit the roles played by a conception within a theoretical account. Ronald Dworkin's legal theory, for instance, suggests that C-Judge is a conception with which legal theorists must compete. We might say that for Dworkin there is no distinction between participant-level conceptions of law and meta-level conceptions of law. On this view, all lawyers, judges, and other participants in legal argument are legal theorists. ${ }^{28}$ Positivists like Hart see themselves as external

28 "Jursiprudence", Dworkin claims, "is the general part of adjudication, silent prologue to any decision at law" (Dworkin, Ronald, Taking Rights Seriously, Cambridge, United States, Harvard University Press, 1977, p. 66). In the Postscript to The Concept of Law, Hart welcomes Dworkin's subsequent limitation of this "claim that the only proper form of legal theory is interpretive and evaluative" (Hart, H. L. A., op. cit., n. 5, pp. 243 and 244), though it is unclear whether Dworkin really does 
to the explanatory object. They are observers who can take note of its features yet can see how, given different circumstances, those features might be different. Interpretivists like Dworkin deny that one can take up an external point of view. Dworkin believes that the manner of conceptualization which occurs at the participant's level is the only appropriate way to conceptualize law, and that to treat law as if it were something one could understand from an external perspective is to misconceive law's nature. For Dworkin, $C$-Judge could never just be something to be described or explained -it is always already a conceptual competitor. But treating C-Judge as being on the same level as C-Law is a contestable methodological choice, not only because it relies upon the mistaken claim that any worthwhile or proper account of law necessarily involves substantive moral-political argument, but also because it places a priori limits on the nature of juridical law itself: law must be justifiable (else it is not law). Hence positivists tend not to think of participant-level conceptions like C-Judge in terms of (1). For a positivist, C-Judge is part of the data we need to describe and explain -it is (3). Judge $\mathrm{X}$ may say $\mathrm{Y}$ about Canadian law, and we will try to describe and explain Y even if we are quite certain that $Y$ is in some sense incorrect. Separating meta-level from participant-level conceptions allows us to include even mistaken participant conceptions in our theoretical account -it leaves (3) as one way to include a conception in our descriptive-explanatory account without our having to evaluate the worth of its content.

\section{Restrictive Methodologies}

Having owned-up to our commitment to describe things as they are and to do so from an external perspective (M1), and having recognized that this entails developing a theo- 
retical explanation which distinguishes between participant-level features and our legal-theoretical claims (M2), we are now able to give a good reason for rejecting $\mathrm{C}$-Pol.

Our problem with $\mathrm{C}$-Pol is neither ontological nor epistemic. We can take the defensible minimalist ontological view that ideas like $C$-Pol and $C$-Judge can be said to exist insofar as they admit of being the product of a descriptive claim. Since our epistemological schema includes a distinction between the participant- and meta-level, the fact that $\mathrm{C}$-Judge and $\mathrm{C}$-Pol are mutually contradictory is not yet cause for alarm. This is so because we can allow that $C$-Judge is possibly mistaken, or that C-Pol applies to a different explanatory object. Even if $\mathrm{C}$-Pol were a conception of the same object we intend to explain, $C$-Pol is pitched at a level of generality and abstraction which has little connection with the questions and puzzles that concern us.

The real problem with $\mathrm{C}$-Pol is that it is methodologically restrictive. If we use $\mathrm{C}$-Pol, then we would effectively be applying it as a filter for the pre-theoretical data which forms the basis of our object of explanation. Our theoretical perspective would hold a priori that Canada's constitution is merely an abstract theoretical entity whose nature is such that it cannot be reasonably claimed that the Charter is a part of it. Before even considering why and how Judge $\mathrm{X}$ offers $C$-Judge, we would be assuming that Judge X's conception is conceptually incoherent. If we accept $\mathrm{C}-\mathrm{Pol}$, then, our explanatory object and hence our meta-level conception of it will be largely predetermined.

In the present case, it seems that we need to know what a constitution is before knowing whether the Charter can be a part of it. From our descriptive-explanatory theoretical perspective, the meaning of the term "constitution" - perhaps it is better to say "the best legal-theoretical provisional definition of "constitution" - is either (a) not equivalent to $\mathrm{C}$-Pol, or (b) is equivalent to C-Pol. If (b) is the case, then we are necessarily led to the conclusion that (c) Canadians do not know what a constitution is. Yet (c) seems highly un- 
likely. The challenge here is analogous to the challenge of knowing whether a stipulative or provisional definition of law is methodologically appropriate. Recall that Cicero's stipulative definition of law avoids many problems in legal theory, including the problem of descriptive/conceptual reciprocity. Yet Cicero's theory is completely undermined if his stipulative definition is incorrect. Moreover, his theoretical methodology does not allow him to revise that definition insofar as his conclusions directly depend upon on it. Cicero's theory of law is not amenable to a posteriori observations which signal a need to modify its explanatory concepts.

The best methodological path to follow is to allow that $C$-Pol may be true, but that for our present purposes it is methodologically inappropriate. We will not try to determine whether (a) or (b) is really the case by engaging directly with deep questions in political theory since that would leave little time for developing a descriptive-explanatory account of the Charter and its relation to Canada's constitution. For the same reason, we want to take note of C-Judge as a feature of Canadian constitution-talk without passing judgement on its descriptive (or moral) correctness with regard to the Canadian constitution.

Two presuppositions allowed to us as methodologically minimalist legal theorists is the presupposition that there are actual legal systems and that widely-accepted paradigmatic cases of such systems, such as Canada's legal system, provide us with enough empirical data to begin a legal-theoretical inquiry. It is clear that Canadians commonly make reference to the Charter as being part of Canadian law as well as being part of "the constitution". Thus it is the case that, whatever it may be from the perspective of absolute theoretical certainty, the Charter has a significant place in the practices commonly thought by Canadians to be related to Canadian law. Instead of trying to choose $a$ priori the best stipulative definition, we can instead develop an account of what Canadians mean when they use that 
term. Of course, a sound theoretical grasp of what they take the term to mean may result in our recognizing that the term is equivocal. Judges, for instance, may mean one thing by it while citizens mean another.

It may also be that whatever conceptual claims we arrive at regarding the nature of law in general may entail that the ordinary use or uses of the term are conceptually incoherent. Before we can make those judgements, however, we need to know what role or roles the constitution plays at the participant-level. Here, as elsewhere, we are assuming that there is a significant relation between the use of a term and a particular concept. In short, we assume that one way to grasp the meaning or partial meaning of a concept is by considering the meaning of the concept-word. This is a useful philosophical methodology of long-standing. It does not commit us to any particular controversial linguistic or semantic position-it does not make us ordinary language philosophers. Ultimately, our best theoretical understanding of a concept may render it inconsistent with most every participant-level meaning given to it. Thus we ought not to assume that our concepts should be dictated or circumscribed by ordinary meaning. To claim that we can begin to develop a theoretical account of a concept by examining its purported use at the object-level does not entail that our theoretical account will not diverge from the participantlevel meanings or uses of the concept-word.

\section{AN INTERIM REPLY TO LEITER}

It is clear that a minimalist descriptive-explanatory approach to the question of how the Charter is related to Canada's constitution is not an instance of ordinary language philosophizing. There may be contradictions between ordinary Canadians conceptions of their constitution, Canadian judges' conceptions of the constitution, and our own theoretical conception of it. Our methodological postulates actually enable us to consider the different participant-level 
conceptions and the roles they play in the social practices which we assume are the basis for Canada's constitution. At the same time, however, we have not decided that the political theorist's conception of the constitution is necessarily false, even though it contradicts our theoretical conception as well as participant conceptions. We decided, instead, that $\mathrm{C}$-Pol is not an appropriate explanatory concept in light of the question we aim to answer, namely the relation of the Charter to Canada's constitution. That may also be the case for C-Judge, which is itself a participant-level conception. We have taken note of a number of different, oftentimes contradictory participant-level conceptions, but none of these has been appropriated so as to engineer the content of our explanatory concept. On that basis alone, then, we can defend the descriptive-explanatory approach from Leiter's claim that it is merely a version of ordinary language philosophy.

Secondly, nothing in our approach makes use of a priori analysis. Leiter's main objection to positivism is that it reverts to appealing to our intuitions in order to secure "analytic truths" arrived at by means of non-empirically-revisable claims. It is clear that the theoretical approach we have considered does none of these things. It does not appeal to our intuitions; in fact, it recognizes that many of our theoretical claims may in the long run be quite anti-intuitive. Nor does methodological minimalism postulate a priori analytic truths. Indeed, it has shown itself to be rather resistant to any such tactic. Recall that we rejected $\mathrm{C}-\mathrm{Pol}$ just because it predetermined our theoretical conclusions, and that we chose instead to develop an explanatory concept by considering the actual social practices which instantiate that which we aim to describe and explain. There is nothing in this which commends "analytic truths" of the sort Leiter condemns.

If methodological minimalism does not appeal to intuitions in any inappropriate way, nor rely on participantlevel concepts to determine the content of theoretical ex- 
planatory concepts, nor prescribe "analytic truths" by means of a priori reasoning, then what remains of Leiter's criticisms? The only remaining contested ground is Leiter's proposed meta-theoretical-evaluative criterion and his demand that we choose our legal-theoretical concepts according to their utility for a posteriori inquiries.

There is an obvious objection to Leiter's proposal. It should at this point be clear that his distinction between $a$ priori and a posteriori inquiry does not do the job Leiter wants it to do. Positivist minimalist legal theorists employ a theoretical methodology and use epistemic norms which further the latter type of inquiry, not the former. We can see this more clearly by considering Stephen Perry's caricature of the descriptive-explanatory methodology. Perry argues that descriptive-explanatory jurisprudence is "a form of scientific enterprise" which "supposes that what does and does not count as law is determined by applying the scientific method" without recourse to judgements regarding moral significance. ${ }^{29}$ By equating descriptive-explanatory legal theory with the "scientific enterprise", Perry obscures an important difference between the actual descriptive-explanatory project espoused by Hart (among others) and Perry's caricature of it (which I shall refer to using his phrase "the descriptive-explanatory method"). This caricature relies upon a superficially plausible but ultimately mistaken definition of the meta-thoeretical-evaluative criterion of "explanatory power".

"A particular theory", Perry opines, "adopts the characterization of empirical phenomena that it does because the theory's proponents believe that characterization has explanatory power". 30 When he notes that "explanatory power is most plausibly understood as referring to meta-theoretical criteria for assessing scientific theories",31 one might take Perry to be using the term in the usual sense, namely

29 Perry, Stephen, “Hart's Methodological Positivism”, op. cit., n. 17, p. 313.

30 Ibidem, p. 320.

31 Idem. 
as a general catch-phrase for the many possible ways an explanation, scientific or sociological or jurisprudential, can commend itself. In fact, however, Perry claims that prediction is the primary aim of a descriptive-explanatory theory of law. ${ }^{32}$ There is, however, no necessary connection between explanatory power and predictive power in descriptive-explanatory legal theory.

Predictive power does not itself speak to the actual relevance of the explanatory concepts used in the theory which offers them. This is especially so for explanations of social phenomena, but explanatory relevance is an important consideration in the so-called hard sciences as well. For instance, the theoretical account of light as a wave provides an answer to puzzles and questions which are less satisfactorily answered by the model of light as a particle, yet the reverse is the case with regard to other questions and puzzles. In at least some instances, either model provides a good explanation, sometimes even a better explanation than the other model, and yet the two models contradict each other with regard to the "real" character of the phenomenon of light. If predictive power is truly important to the scientific method, it is because that method relies on falsifiable generalizations in order to mediate between sound descriptive claims and valuable explanatory concepts.

Thus we have good reason to reject Perry's imposition of a dichotomy between "predictive" scientific explanations and jurisprudential explanations which employ general concepts that do not maximize or even realize predictive power. Predictive power is a theoretical value only insofar as it helps to establish the relevance of the explanatory concepts to the phenomenon under investigation. Conversely, a concept's predictive capacity may be of practical value regardless of its utility in providing a sound explana-

32 Ibidem. I concur with Avner Levin, who wonders whether "Perry is stacking the deck against descriptive-explanatory methodology in his focus on prediction" (Levin, Avner, "The Participant Perspective", Law and Philosophy, vol. 20, 2007, p. 582). 
tion of that phenomenon. Perry's account of the relationship between the theoretical values appropriate to (scientific or legal-theoretical) descriptive explanations and the theoretical value of predictive power is incorrect.

We ought in any case to reject predictive power as an appropriate meta-theoretical-evaluative criteria for descriptive-explanatory theories of law. This is so because law may change. I do not mean merely that particular laws or particular legal systems may change, but rather that the phenomenon of juridical law is not static. Juridical law is the result of human social institutions and practices. If it were to aim to maximize predictive power, a theory which also aims to describe law "as it is" would be unable to account for law as it may be at some future point. In other words, a theory of law which attempts to commend itself in light of two particular meta-theoretical-evaluative criteria -descriptive accuracy and predictive power- would almost certainly be forced to sacrifice the former in order to fulfill the latter. ${ }^{33}$

One of the virtues of descriptive-explanatory legal theory is that it is flexible or open-ended: should the institutions and practices of law change, the theory will aspire to modify its account of those institutions and practices accordingly. Maximizing explanatory power by predicting future behaviour is antithetical to that approach. Adhering to the methodological principle of descriptive/conceptual reciprocity is not. Hart's theory of law does not aim to predict anything at all, at least in the usual sense of scientific prediction. He actually observes that "there is much that is questionable, indeed blinding, in the attempt to force the analysis of legal concepts or of any rules into the framework adapted for the

33 To clarify: my claim is not that a descriptive jurisprudential theory committed to only these two meta-theoretical-evalutive criteria is incoherent; rather, my claim is that a descriptive jurisprudential theory whose set of meta-theoretical-evaluative criteria included these two, perhaps even among others, is incoherent. 
empirical sciences". ${ }^{34}$ Given that Hart is so clear on this matter, it is puzzling that Perry tries so hard to force Hart into the position of being either a "real" scientist or a "real" legal theorist. It is all the more puzzling given that the meta-theoretical-evaluative criterion of explanatory power does not support Perry's diremption of Hart's actual methodology into a descriptive and a conceptual one; indeed, it suggests quite the opposite, namely that descriptive claims and explanatory concepts are reciprocal components of most any good theoretical explanation, as opposed to a useful practical technique.

Perry presupposes that, with regard to descriptive explanations, there is only one set of meta-theoretical-evaluative criteria, and that the content of that set is fixed. He argues that a scientific theory has explanatory power only if it has predictive power, that predictive power is not an appropriate evaluative criterion for (at least some forms of) jurisprudential theory, and thus that jurisprudential explanations must make use of moral argument. 35

Hence Perry jettisons the idea that meta-theoreticalevaluative criteria are applicable to legal theories, finding that Hart's positivist project is flawed in that it is too scientific (according to Perry's idiosyncratic understanding of the nature of scientific inquiry). Interestingly, Leiter's own caricature of the descriptive-explanatory methodology of legal positivism is equally unsuccessful at portraying it as not scientific enough. While one could set aside Leiter's critique for this reason alone, it is not enough to show that Leiter's polemic against so-called linguistic-turn philosophers undermines his critique of legal positivism. Insofar as positiv-

34 Hart, H. L. A., "Scandanavian Realism", Essays on Jurisprudence and Philosophy, Oxford, Great Britain, Oxford University Press, 1983, p. 162.

35 Here again I concur with Levin. "A theory of law, as Perry is well aware, differs from a scientific theory seeking to predict experimental results. Yet this does not turn descriptive-explanatory methodology into a methodology inadequate for legal theory. At most it is an argument against the meta-theoretical criterion of prediction when evaluating the success of theories of law" (Levin, Avner, op. cit., n. 32, p. 582). 
ist theories of law are amenable to revision, and insofar as they aim to produce an accurate description and powerful explanation of their subject matter, then they must actually compete in the arena of what Leiter calls a posteriori inquiries. The question is not "Should we accept Leiter's proposed meta-theoretical-evaluative criterion of aiding a posteriori inquiry?" but rather "Is positivism a better means to describe and explain law than the competing a posteriori methods of inquiry?"

Leiter's critique of positivism makes it clear that he would prefer a "naturalized jurisprudence" based on "which way of cutting the causal joints of the social world works best". 36 This "primarily methodological" commitment to naturalistic jurisprudence is more a form of theory and concept choice than a radically different way of describing and explaining law. In most respects, the aims and theory-guiding norms of naturalistic jurisprudence and the social-scientific inquiries it is meant to assist are comparable to the aims and theory-guiding norms of descriptive-explanatory legal theories such as legal positivism. "The motivation for demarcating the legal/non-legal in essentially Hard Positivist terms is, for most social scientists, to effect an explanatory unification of legal phenomena with other political and social behavior". ${ }^{37}$ In short, Leiter wants legal philosophers to join with their social-scientific colleagues, and if that requires choosing a concept of law suitable for several different methodological inquiries, then that is what we should do. "If social science cuts the causal joints of the legal world in Hard Positivist terms, is that not a far more compelling reason to work with that concept of law as against its competitors?".38

36 Leiter, Brian, op. cit., n. 7. Some theorists, such as Jules Coleman, call this “consilience". See, e. g., Coleman, Jules, op. cit., n. 17, pp. 38-40.

37 Idem. See also my discussion in Burge-Hendrix, Brian, "Two Perspectives on Legal Theory", Canadian Journal of Law and Jurisprudence, vol. 16, 2003, p. 338 and p. 341.

38 Leiter, Brian, op. cit., n. 7. 
There is nothing inherently wrongheaded with the notion that a theory might be considered better if, besides providing a good explanation of its subject matter, it also is of assistance to other forms of theoretical inquiry into related matters. Hence what we might call "interdisciplinary assistance" is perhaps a valid meta-theoretical-evaluative criterion. It is a sufficient criterion for choosing either (i) one explanatory concept over another, e.g. an exclusive rather than an inclusive concept of the rule of recognition, or (ii) one legal theory over another, e. g. exclusive over inclusive positivism?

Setting aside his critique of conceptual analysis, we can still note that Leiter opts for the Hard Positivist explanatory concept because it better fits with social-scientific inquiry into law. Liam Murphy prefers Hard Positivism for its putative moral consequences. Both Leiter and Murphy invoke additional theory-guiding norms in order to solve the problem of epistemic uncertainty and to allow for further legal theoretical inquiry unbound by that uncertainty. Leiter's norm is that of interdisciplinary assistance, while Murphy's is that of bringing about good moral consequences.

We should reject Murphy's approach because it predetermines the features of an explanatory concept for worthy but explanatorily irrelevant reasons. That is, Murphy argues that we ought to choose our legal theory on moral grounds rather than according to its ability to describe and explain its subject matter. Leiter makes a similar though more subtle error. His theory-guiding norm is counterproductive to his stated aim of providing a more epistemically correct jurisprudential account. In this section we shall see that, while ceteris paribus interdisciplinary assistance is a worthy aim for any theoretical inquiry, this aim is subservient to the primary aims of any good theoretical explanation: to explain its subject matter. Leiter's choice of Hard Positivism over Soft Positivism on the basis of interdisciplinary assistance overlooks the primary aim of positivist legal theory and leads to the very situation he wishes to avoid: the $a$ pri- 
ori determination of significant features of law in advance of an inquiry.

\section{The Division of Labour Argument}

Leiter advocates Hard Positivism because its explanatory concept of law, and in particular its exclusivist version of the rule of recognition, is more convenient for social-scientific inquiry into law. In this sense he chooses his legal theory on social-scientific grounds rather than legal-theoretical grounds. This is a coherent position, but it is also a position which a legal theorist may reasonably reject. Perhaps social-scientific inquiry into law is best served by the exclusive rather than the inclusive explanatory concept of a rule of recognition. It does not follow, however, that legal-theoretical inquiry in general is best served by that concept for that reason.

Unless we are certain of the accuracy of a particular conception which appears to have legal-theoretical utility or relevance, such as the political theorist's concept of the constitution which we discussed in the previous section (C-Pol), we do not know whether it would be a good or bad conception to accept for our legal-theoretical purposes. Once we see that this is the case, it will be clear that the same holds for accepting a social-scientific concept of law for use in a jurisprudential account.

We might be tempted to take up C-Pol for our descriptive-explanatory purposes because it has been developed through a long tradition of careful and reflective political-theoretical inquiry. Perhaps, we might think, political theorists can be presumed to have a particularly insightful account of their own field of study. They have, of course, closely studied and puzzled-over the nature of political practices and institutions. We legal theorists have paid more attention to other things, namely the nature of legal practices and institutions. If each discipline were to accept the authority of the other, this division of labour would 
benefit us all-legal theorists could defer, where appropriate, to political theorists, and vice versa. Let us call this the Division of Labour Argument.

Unfortunately the Division of Labour Argument is unsound. First, it assumes that there is sufficient consensus amongst political theorists to constitute authoritative and well-established explanatory concepts from which we legal theorists might pick and choose. We know, however, that there is no more of a consensus among political theorists regarding the nature of extremely important concepts, e.g. the nature of political authority, than there is among legal theorists regarding the nature of other extremely important concepts, e.g. the nature of legal authority. Secondly, even if there were sufficient political-theoretical consensus on a concept relevant to legal theory, it does not follow that this consensus of agreement among political theorists was arrived at by means of methodological practices and metatheoretical commitments which are acceptable to descriptive-explanatory legal theorists. Political theory may, for instance, require the direct moral evaluation of its explanatory object.

The third reason why the Division of Labour Argument is unsound is the most important. Suppose that (i) there is a consensus among political theorists as to the best account of the nature of constitutions, and (ii) this account is arrived at by means of methodological practices and metatheoretical commitments which are identical to those of descriptive-explanatory legal theorists. Does it follow that (iii) the best political-theoretical account of constitutions is also the best legal-theoretical account?

Oddly, (iii) does not follow from (i) and (ii). We tend to think that because a theoretical approach can be defined by its methodological practices and its meta-theoretical commitments - as when we characterized the minimalist positivist approach to law- these practices and commitments will, given the same set of pre-theoretical data, necessarily determine the results of the theoretical account. 
But that is not how things actually work, for there is no conclusive or "objective" way to judge the merits of legal theories. Perhaps the most difficult methodological problem in legal theory involves the task of evaluating the available theories of law. One way to adjudicate between better and worse theories of law is to determine which theory best enables us to answer the questions and solve the puzzles that concern us. Joseph Raz observes that an "explanation is a good one if it consists of true propositions that meet the concerns and puzzles that led to it, and that are within the grasp of the people to whom it is (implicitly or explicitly) addressed". 39 A legal theory which makes such an explanation possible would therefore be better than one which prevents it.

We can refer, then, to a meta-theoretical-evaluative criterion of explanatory relevance: the merit of an explanation is relative to the queries it is meant to address. If taken on its own, the criterion of explanatory relevance could be seen as implying that there can be no "best" theory of law, only different explanations directed at different concerns. In other words, explanatory relevance makes explanatory relativism unavoidable: there is no objective way to judge the merits of legal theories apart from their success at addressing the questions and puzzles they aim to answer, hence the standards of theoretical success are necessarily relative to explanatory aims rather than being objectively set for all legal theories.

The fact of explanatory relevance entails explanatory relativism: some standards of theoretical success are necessarily relative to explanatory aims rather than being objectively set for all theories. Two theorists could share a commitment to the pursuit of truth and the general aim of providing a descriptive-explanatory account based on the same set of pre-theoretical data. Despite this congruence of method and aim, however, they may still arrive at different conclu- 
sions depending on which questions they decided were important to answer or which puzzles caught their attention.

It is not that every theoretical account is necessarily different simply because it is offered by a different person. We can attribute a methodology or meta-theoretical commitment to a type of theory. It is perfectly sensible, for instance, to speak of positivism's commitment to describing law as it is. When one theory, however, focuses on different questions and puzzles than another, its account of its explanatory object will be different than the other's account. This is so even if both theories begin with the same set of pre-theoretical data, for it is not just the data to be explained but also the questions and puzzles regarding that data which drive the theoretical accounts. An account of phenomenon $X$ can be judged superior to other accounts on many grounds. Some of these grounds are the pure metatheoretical-evaluative criteria applicable to all theories. Explanatory relevance is meta-theoretical-evaluative criterion, but there is a sense in which this criterion is objective and a sense in which it is not. It is objective in that a theory of $\mathrm{X}$ is better insofar as it addresses the questions and puzzles which are of interest to theorists of $\mathrm{X}$. But the questions and puzzles may vary, and the criterion is met (or not) only in relation to them-in this sense it is impure.

Consider another meta-theoretical-evaluative criterion, namely the idea that a theory is better insofar as it does not multiply abstract entities beyond necessity. We can say that this criterion applies as it were objectively to all theories. But the goals of different theories, e. $g$. the level of abstraction a theory intends to pitch its account at, are what determines the necessity. A theory of the practice of arithmetic will require fewer abstract entities than a theory of the practice of factoring prime numbers. The important point is that the questions and puzzles are as determinative of theoretical results, e.g. an account of what a constitution is, as are the theory's methodological practices and metatheoretical commitments. Thus the descriptive-explanatory 
political theorist who aims to give an accurate description and insightful explanation of the Canadian Charter may arrive at a conception of the constitution which is well-suited to the question "What is the constitution such that Canada is able to assert itself as a nation-state?". Yet that conception may not be so well-suited to a descriptive-explanatory legal theorist's question - "What is a constitution such that the Canada's Supreme Court can render Parliamentary legislation to be of no force and effect?'- or that of a moral theorist - "What is the constitution of Canada such that it does or does not evince a moral failure on the part of most Canadians to treat Aboriginal peoples with due respect?". ${ }^{40}$

I have given three reasons for rejecting the methodological possibility of using $\mathrm{C}-\mathrm{Pol}$ in our own legal-theoretical descriptive-explanatory account. The first is that our generalized epistemic uncertainty about the nature of law, and of the nature of the elements of law (including legal practices and social institutions), disallows the use of $C$-Pol at the outset of our inquiry - that is, as a filter for the pre-theoretical data- given its obvious contradiction with actual social practices. ${ }^{41}$ I argued, secondly, that we have no grounds to adopt that conception even if political theorists in general agreed on its accuracy and explanatory power. This is so because, thirdly, the accounts of phenomena presented by descriptive-explanatory theorists (of whatever discipline) are guided not only by methodological practices and meta-theoretical commitments, but also by the questions and puzzles which they aim to answer.

40 There is, it seems to me, something to be said for holding to some form of explanatory relativism, such that our critical projects make use of a critical methodology, our descriptive projects employ descriptive methodologies, and so forth. Explanatory relativism is also an important consideration when we have more than one theoretical goal. It can be argued, for instance, that a moral critique of law is better accomplished by first giving a morally-neutral, descriptive-explanatory account of it. If this is so, then a critique of law in general which is aimed at our moral concerns regarding law requires two well thought-out theoretical methodologies: a morally-neutral descriptive one and a morally-informed critical one.

$41 \mathrm{C}$-Pol may well prove to be the best conception even given its contradiction of $C$-Judge. But we cannot make that determination now unless we take up C-Pol as a stipulative definition. 
If the account of explanatory relativism I have just given is sound, then we not only have reason to be wary of using theoretical conceptions based on different approaches to the pre-theoretical data, such as $\mathrm{C}$-Pol, we also have reason to doubt any meta-theoretical-relational claim to the effect that descriptive-explanatory legal theory is necessarily dependent upon the conceptual claims of other theoretical accounts-even when those other accounts deal with the same pre-theoretical data. Explanatory relativism entails that different theoretical accounts may develop from the same explanatory object despite the use of identical methodological techniques and the presence of identical commitments to the same meta-theoretical values.

\section{Methodology and Convenience}

Brian Leiter's attempt to dismiss legal-theoretical uncertainty by appealing to the theory-guiding norm of interdisciplinary assistance is a mistake. Even if Hard Positivism were a better legal theory for the purpose of developing social-scientific explanations of law, that (supposed) fact would not provide a good reason for positivists to choose Hard Positivism since the social-scientific theories Leiter wants to encourage tell us, really, quite little about about a number of the features of law which positivists consider to be important. Yet Leiter seems to be quite comfortable with abandoning any attempt to explain them.

In his argument contra non-naturalistic legal theory, Leiter makes some bold claims. The natural lawyer who objects to "cutting the joints of the social world" on the basis of convenience to social-scientific inquiry cannot, Leiter opines, offer good reasons for considering untestable or vague notions to be factors in how law works: "many of the candidate non-law explanatory factors at issue $(e . g$. an ideological commitment to the platforms of the Republican 
Party) are not plausible candidates for being legal norms". ${ }^{42}$ Here Leiter is being more than just uncharitable. Consider another "ideological commitment" which may or may not be a "non-law explanatory factor": a commitment to the rule of law. It is not implausible to claim that the rule of law is a necessary feature of legal systems, but it is very difficult to determine what the rule of law is or which practices actually qualify as ruling according to law. The rule of law, as an ideological commitment or as a particular form of social control, is not something that can be ascertained through empirical inquiry. Unless, of course, one employs a socialscientific or naturalistic accounts of law which makes use of a stipulative definition of what it is, just as Leiter would have jurisprudents employ a stipulative definition of legal validity.

Yet Leiter's naturalistic approach offers no stronger defence of its presupposition against considering "non-law explanatory factors" than convenience:

[I]t is not like the characterization of these factors as non-legal by social scientists is arbitrary and unmotivated: the moral and political factors invoked to explain decisions do not, for example, appear in the decisions, or in the explicit rationales for the decisions; they are often hidden and hard to detect, which make them quite unlike any of the paradigm instances of legal norms, like statutory provisions or precedent. 43

In this quotation, what has Leiter offered in support of pedigree criteria for legal validity other than (i) they are easy to see, and (ii) they are especially easy to see given the difficulty of observing other potential legal norms?

Even when an "explanatory factor" can meet clear pedigree criteria, however, it does not follow that it can be explained wholly in seemingly empirical social-scientific terms. As a matter of fact, reference to "the rule of law" has

42 Leiter, Brian, op. cit., n. 7.

43 Idem. 
on occasion been quite explicit, though nonetheless difficult to qualify and quantify through empirical study. Much of the Canadian Supreme Court's opinion in Re Manitoba Language Rights explicitly rests upon the perceived importance of the rule of law, e. g. "The principle of rule of law, recognized in the Constitution Acts of 1867 and 1982, has always been a fundamental principle of the Canadian constitutional order". ${ }^{44}$ Although explicitly posited, the participant-level concept of "the rule of law" is not readily described or explained by a naturalistic analysis of the type Leiter advocates. Yet it is absolutely central to Canadian constitutional jurisprudence. In the Manitoba Language Rights reference it was the rule of law which provided the only jurisprudential bulwark between Manitoba's having a legal order and its not having one. The Court first noted that, were it pressed to decide, it would have to find that Manitoba had no legal order:

The Court must declare the unilingual Acts of the Legislature of Manitoba to be invalid and of no force and effect. This declaration, however, without more, would create a legal vacuum with consequent legal chaos in the Province of Manitoba. The Manitoba Legislature has, since 1890, enacted nearly all of its laws in English only. The conclusion that all unilingual Acts of the Legislature of Manitoba are invalid and of no force or effect means that the positive legal order which has purportedly regulated the affairs of the citizens of Manitoba since 1890 is destroyed and the rights, obligations and any other effects arising under these laws are invalid and unenforceable. From the date of this judgment, the Province of Manitoba has an invalid and therefore ineffectual legal system until the Legislature is able to translate, re-enact, print and publish its current laws in both official languages. ${ }^{45}$

44 Re Manitoba Language Rights, [1985] 1 SCR 721, 724.

45 Idem. 
In the next paragraph, however, the Court suggests that it is "necessary, in order to preserve the rule of law, to deem temporarily valid and effective the Acts of the Manitoba Legislature, which would be currently in force were it not for their constitutional defect". ${ }^{46}$ Although the concept of the rule of law is explicitly posited in case law and in constitutional documents, it is not something which can be explained by "cutting the joints of the social world" such that its political/ideological force is ignored.

A similar argument against Leiter's support of Hard Positivist explanatory concepts might be made with regard to the putative morality of a legal system. Consider the old jurisprudential chestnut of the Nazi regime's supposed legal system. Surely the fact that it is difficult to determine whether a "borderline case" of a legal system counts as a legal system is not a good reason for a legal theorist to presuppose that such difficult or recalcitrant data merits exclusion from consideration, or should simply be definedaway to further empirical study and avoid uncertainty? Yet Leiter's argument in favour of the Hard Positivist concept of law amounts to not much more than a claim to convenience and, moreover, an unreasonable insistence (given the subject matter) on evidentiary certainty.

Leiter's attempt to invoke a presumption in favour of generality is more sensible, but equally mistaken. He suggests that

...the legal/non-legal demarcation in empirical social science usually reflects more general explanatory premises about the psycho-social factors that account for behavior, well beyond the realm of the legal. The motivation for demarcating the legal/non-legal in essentially Hard Positivist terms is, for most social scientists, to effect an explanatory unification of legal phenomena with other political and social behavior. ${ }^{47}$

46 Idem.

47 Leiter, Brian, op. cit., n. 7. 
One need not impugn the motivation or even the effectiveness of social-scientifc inquiry to understand why that form of inquiry may not be of much help to legal theory. It is good that social scientists also aim to develop general and ever more comprehensive explanations. Yet those explanations elucidate some features of law at the expense of others. Just as the political scientist's explanatory concept of a constitution can obscure the role of Canada's Charter as a typical feature of modern constitutional legal systems, the social scientist's focus on observable "political and social behavior" relies upon assumptions about what counts as political or social behaviour. Of course, inquiry cannot begin without such assumptions, and different explanatory aims may require different assumptions. But that is a reason which counts against choosing an explanatory concept according to the assumptions of other types of inquiry.

\section{WRITTEN AND UnWRITTEN RULES}

A legal theory whose "picture of courts... fits them to a broader naturalistic conception of the world in which deterministic causes rule, and in which volitional agency plays little or no explanatory role" 48 is unhelpful for enabling us to understand law in light of the social practices of a judge, lawyer, or citizen who is appealing to her (supposed) constitutional rights, however powerful a non-volitional, radically empirical theory might be at explaining cause-and-effect relationships. To see why this is so, let us reconsider our earlier example: Canada's legal system. Furthermore, let us examine those features of Canadian legal practices which a naturalistic jurisprudence cannot fully explain: its participants" conceptions. And let us consider these conceptions not only when they are explicitly specified in law, but also as they are reflected in the activities and efforts which make law, and Canadian law in particular, possible. Earlier 
I suggested that a commitment to the rule of law is part and parcel of a legal system, but that Leiter's pedigree criteria of what does or does not count as a "law explanatory factor" cannot describe, much less explain, that commitment. Now I want to suggest that a naturalized jurisprudence which cuts the joints of the social world in strictly empirical terms cannot account for another significant feature of modern legal systems: the legal right to vote.

To consider the general idea of a legal right to vote, and in particular what that right is as it is actualized in Canada, we must first be very careful not to presume that only one participant-level conception is part of Canadian legal practices or institutions, or of the social practices or institutions directly related to them. Now that we are analysing the participant- or object-level - the actual social practices and institutions which appear prima facie to be part of or directly related to Canada's legal system - we should also keep in mind the fact that we are aiming to develop an account of that phenomenon as it actually is. We are not trying to discipline or otherwise correct the conception or conceptions therein by imposing or replacing them with our own theoretical conceptions. In fact, at this point in our analysis we do not yet have a working theoretical conception of our own, never mind a considered opinion regarding the truth, accuracy, conceptual coherence, or moral worth of the various possible conceptions.

What better place to begin than with some comments by the Supreme Court of Canada's regarding Canadians' legal right to vote? To set up the context of the voting franchise in Canada, let us briefly digress so as to consider the elements of Canada's constitution. It shall become clear that some of these are the very sort of "non-law explanatory factors" which naturalistic jurisprudence ignores.

In the so-called Patriation Reference, the Court distinguished between two types of constitutional rules: written and unwritten. "Those parts of the Constitution of Canada which are composed of statutory rules and common law 
rules are generically referred to as the law of the Constitution". ${ }^{49}$ Section 9 reads: "The Executive government and authority of and over Canada is hereby declared to continue and be vested in the Queen." As the Court noted, the practical implications of this provision for "Executive government and authority" are somewhat unclear. Hence "one must look to the common law to find out what they are, apart from authority delegated to the Executive by statute". ${ }^{50}$ And so, in the opinion of the Supreme Court of Canada, Canadian constitutional law comprises both legislative enactments and rules of common law. Common law rules acquire a written form when they are recognized in judicial decisions. These decisions become precedents, or what is often called "case law". We can thus say that the "statutory rules and common law rules" which make-up Canadian constitutional law are (according to the Supreme Court of Canada) always written or source-based rules. For now we shall leave aside the question of whether the Court's account of "constitutional law" is ontologically sound or epistemically correct. Our aim is merely to elucidate the conceptions already at work at the participant level.

In light of its political institutions and their inter-relationships, Canada can be categorized as a federalist parliamentary democracy. Insofar as it is a democracy, the nation-state of Canada would not exist and could not continue to exist in any contemporarily recognizable form unless Canadians had effective voting power. In Canada, however, there is a paradox regarding the efficacy of the legal right to vote. In order to explain how Canadians' legal right to vote actually effects a change of government, the

49 Re Resolution to Amend the Constitution of Canada [1981] 1 SCR 753. The example used is that of Sections 9 and 15 of the British North America Act. The B.N.A. Act was Canada's primary written constitutional document until 1982, when Canada's constitution was "patriated" - freed from its (at that point almost entirely symbolic subservience) to the ruling queen or king of Britain- and the Constitution Act, 1982 incorporated into it. Subsequent to patriation, the B.N.A. Act was renamed the Constitution Act, 1867.

50 Idem. 
Court makes reference to another category of the elements of the Canadian constitution-a category distinct from "constitutional law".

Canadians' legal right to vote is paradoxical in that it is merely posited. I say "merely posited" because, in Canada, the efficacy of one's valid vote is legally unenforceable. The Court rather ironically observes that

...many Canadians would perhaps be surprised to learn that important parts of the Constitution of Canada, with which they are the most familiar because they are directly involved when they exercise their right to vote at federal and provincial elections, are nowhere to be found in the law of the Constitution. For instance, it is a fundamental requirement of the Constitution that if the Opposition obtains the majority at the polls, the government must tender its resignation forthwith. But fundamental as it is, this requirement of the Constitution does not form part of the law of the Constitution. ${ }^{51}$

It is a constitutional convention which ensures that, should Canadians vote a government out of Parliament, that government will relinquish power.

By law, then, Canadians have the right to vote-yet there is nothing in Canadian positive law to ensure that use of this right will effect a change of government. If a Canadian citizen were denied his right to vote, he could go to court and obtain a legal remedy. But that legal remedy would pertain only to having the legal right to vote; the remedy would not and could not (according to Canadian positive law) ensure the efficacy of that right. If, for instance, every Canadian of voting age exercised his or her legal right to vote in a federal election, and it were the case that every single vote was for the opposing rather than the ruling party, and it were also the case that the ruling party refused to step down and continued, instead, to act as the official government -if all these facts were to be true- then there is absolutely nothing in Canadian law that could be

51 Idem. Emphasis added. 
done to directly force the ruling party to relinquish power. Nor, according to the Court, does the law of the Canadian constitution provide for a number of other "essential rules of the Constitution" upon which Canadians depend and which they would be quite surprised to see broken. 52

Clearly it is the case that Canadian constitutional conventions are very important to the political life of the nation. Yet the basis of a constitutional convention is not positive law in the strict sense - law set down in writing or by pronouncement - but rather "custom and precedent" where precedent is understood as accepted but unwritten rules of institutional practice. ${ }^{53}$ A significant characteristic of Canadian constitutional conventions is that they exist "merely" as a continuing historical practice on the part of legislative officials. A constitutional convention is a "continuing historical practice" rather than simply a "continuing practice" because it is reflectively adhered to. If Canadian legislative officials just happened to switch governments given circumstances similar to those in which governments were changed in the past, then we would not have a conventional practice which guides the behaviour of the individual members of a group. We would not, in other words, have a convention.

It is worth noting, incidentally, that a strictly empirical social-scientific inquiry into the existence of a particular constitutional convention could not readily observe the difference between a change of government made according to this sort of convention and a change of government made in ignorance of it yet, perhaps coincidentally, in a superficially identical way. That may sound like an extreme example,

52 For example, there is no provision in Canadian constitutional law for the Prime Minister of Canada to resign and call an election if and when his own political party fails to support him in a parliamentary vote. This is so despite the clear fact that so-called "votes of non-confidence" have effected changes of government in Canada.

53 Idem. Constitutional conventions are "usually unwritten rules" although they are sometimes written down, for example in the preamble of constitutional document. 
but the point stands: unwritten conventions based on practices which are reflectively adhered to yet just done instead of explicitly done according to the practice are not the sort of social practices which are amenable to empirical observation and categorization. And yet, as we can see in this instance, Canadians rely on exactly this sort of convention.

At any rate, what is especially important - what makes a difference at the participant-level - is that constitutional conventions are "precedents established by the institutions of government themselves". ${ }^{54}$ Moreover, the constitutional conventions of Canada are not "in the nature of statutory commands which it is the function and duty of the courts to obey and enforce". 55 Breaking a constitutional convention invites no formal judicial response, merely the certainty of widespread disapprobation and severe criticism.

The existence of a legal right to vote is a characteristic feature of the legal systems of modern democracies. An account of legal rights in modern democratic societies must surely consider the right to vote if it is to be thorough descriptive explanation of how such societies work. A descriptive-explanatory theory of law may not need to describe and explain the concept of a legal right to vote for, after all, being a democratic nation is not a necessary condition for having a legal system. But a good general theory of law must give an account of legal rights, or of the practices which underlay what we call "legal rights", and this account ought in principle to be capable of dealing with actual existing legal rights, such as Canadians' right to vote.

\section{PARTICIPANT PeRspectives}

Three significant fixed points of reference arise from our observations regarding the apparent state of just one aspect

54 Idem.

55 "The conventional rules of the Constitution present one striking peculiarity. In contradistinction to the laws of the Constitution, they are not enforced by the courts" (idem). 
of Canada's constitution as it was in 1981. Any good descriptive-explanatory account of Canada's constitution (as it then was) must take account of the following points:

- P1 - The Supreme Court of Canada explicitly claimed that Canada's constitution consists of both written and unwritten elements, namely positive law (including codified principles of common law) and historical conventions.

- P2 - According to the Court, the effectiveness of the legal right to vote is not secured by the adjudicatory officials of Canada's legal system. This is so because its efficacy is not a matter of law at all.

- P3 - The so-called ordinary Canadian's notion of a right to vote goes beyond the Court's strict definition of constitutional law (which includes only the written elements of Canada's constitution) insofar as the legal right to vote entails, from the perspective of the "ordinary Canadian", that the government is legally obligated to act in accordance with the result of that vote.

P1-P3 are defensible descriptive claims; they are "fixed points of reference." In other words, they appear to corollate with observable characteristics in the physical world, e.g. the texts produced by the Supreme Court, as well as some basic speculative propositions regarding mental states, e.g. that most Canadians would be surprised to find that they had no legal recourse should a government refuse to step down upon being voted out of power. The three points are thus "fixed" by their presence in a particular context. Additionally, they are "points of reference" insofar as any thoroughgoing descriptive-explanatory account of the relevant pre-theoretical data must make reference to and explain them.

It is at least possible to give such an account without aiming towards a particular moral-political result, and in the process of developing that account some interesting 
conceptual questions will arise. ${ }^{56} \mathrm{P} 1-\mathrm{P} 3$ are significant features of Canadian institutional structures and socio-political practices. P1 speaks to the relationship between positive law and the Canadian political system, as Canada's Supreme Court understands it. P2 reflects, among other things, the limits of legal-judicial authority in Canada. P3 signals an important difference between what ordinary Canadians take to be part of the content of their legal right to vote, and what the supreme judicial authority considers that content to be. We could say "effectiveness" rather than "content" and P3 would still stand. A legal positivist could pursue many different lines of inquiry by focusing on these fixed points of reference, but P2 and P3 entail one particularly important observation, namely that the ordinary Canadian's understanding of a legal right to vote contradicts the Supreme Court's understanding of that legal right. This is a simple observation, yet it leads directly to important methodological issues. Some are familiar, but at least one is usually overlooked.

The first of the familiar methodological issues has to do with the general and descriptive aims of positivist legal theory. Traditional positivists aim to describe and explain a type of common yet complex social institution ordinarily referred to as a legal system. At least some positivists also aim to develop a general theory of law - a theory which accounts for the necessary features of all legal systems wherever and whenever they exist. A general theory of this sort which also purports to be descriptive, and which does not identify what is or is not juridical law according to a stipulative definition (as Ciceronian legal theorists have done), must take its cues from extant legal systems in order to develop a suitably abstract and general account of law. A general and descriptive theory of law, in other words, must

56 For example: "Given that it is posited in law but legally nonactionable, is a Canadian citizen's right to vote properly characterized as a legal right?" - "Can a legal right's efficaciousness depend on an historical convention?" - "Ought we to distinguish between the form or appearance of a legal right and its content or force?". 
reach its theoretical conclusions by considering what appear to be actual legal practices and institutions. Hence the boundaries of what does or does not count as an actual legal practice or institution are not set a priori, but are as it were "discovered" through the process of theoretical inquiry.

Another by now familiar methodological issue is the methodological principle of descriptive/conceptual reciprocity. It is one thing to allow that the abstract, generalized account of law has flexible boundaries in the initial stages of theoretical inquiry. It is, however, quite another matter to know when to make a conclusive claim regarding the real status of any particular practice or institution which initially appears to be a legal system. The descriptive claims made by P2 and P3 are not abstract or general. Rather than stating true propositions about the nature of legal systems, P2 and P3 are descriptive claims made on the basis of an empirical observation of what may be an actual legal system. Taken as simple observations, P2 and P3 are unproblematic. To an external observer of the context in which they apply, they are merely two features amongst many in a vast amount of theoretical data having to do with the modern nation-state of Canada. They are reports of what the Supreme Court of Canada says is the case, and an observation of (or a speculation regarding) what ordinary Canadians seem to assume is the case. To a legal theorist, however, these same observations are data-points which appear (at least initially) to relate to the very idea of a legal system. They are theoretically significant in part because of the theorist's provisional definition of law.

Here is the methodological issue which is often overlooked: from the legal-theoretical perspective of one who aims to develop a descriptive and general account of juridical law, it is absolutely necessary to account for the difference between the Supreme Court's view of the content of the legal right to vote, and the ordinary Canadian's view of that right. Why? The concern here is not just that ordinary Ca- 
nadians have a particular (possibly mistaken) conception of their right to vote; rather, the meta-theoretical concern is that this participant-level conception is part of what makes possible the social practices of voting and legislating. Hence it is important to account for that conception regardless of its epistemic standing, either with regard to the very idea of legal rights or more specifically with regard to the actual legal rights given by Canadian law. Likewise, the Supreme Court's conception must also be taken into account. Although it too may be mistaken, it is part of and reflects the social practice of adjudication.

In the Canadian legal system, the Court's conception has more force. In that context, the ordinary conception is simply mistaken. In the Canadian political system, however, we might reasonably infer that it is the ordinary conception which has more force. If the citizens of Canada vote the ruling political party out of office, that party will leave not because it has a legal duty to do so, nor merely out of the desire to continue an historical convention, but mostly because the political consequences of ignoring the ordinary conception of the right to vote would be tantamount to revolution. Thus P2 and P3 entail two very different conceptions of a clearly-specified legal right as well as two very different ways in which that right has efficacy or force. The citizen perceives the right as having a particular content or power or force in virtue of its being a right granted by and (presumably) secured by law. The Supreme Court of Canada, conversely, perceives the legal right as having no legal force, despite its obvious political efficacy. There is a contradiction here, but it is not to be dismissed as a logical contradiction-it is an apparent contradiction between social practices which are necessary to the existence of Canada and its legal system.

Describing and explaining this contradiction presents a challenge for legal theorists. It is exactly the sort of challenge which positivism is well-suited to consider, and which naturalist jurisprudents, among others, cannot readily con- 
sider. As legal theorists we want, ideally, a single, suitably general, descriptively accurate concept of what a legal right is. Yet in the Canadian context, different conceptions of the legal right to vote exist at the participant-level. We cannot simply chose one participant-conception over the other, but neither can we dismiss them in favour of an a priori concept of our own.

Insofar as they aim to describe law as it is, descriptive-explanatory legal theorists do not advocate the outright dismissal of participant-conceptions. Rather, they aim to account for and make sense of them. On rare occasions, they may decide that a particular participant-conception is necessarily mistaken, but for the most part, the descriptive-explanatory legal theorist attempts to develop explanatory concepts which are sufficiently general as to encompass as many actual participant conceptions as possible.

Nonetheless, for the sake of expediency we might be improperly tempted to find reasons to dismiss either the $\mathrm{Su}-$ preme Court of Canada's conception or the ordinary Canadian's conception. One temptation might be to distinguish between politics and law. We could say that the ordinary Canadian's conception of the legal right to vote is political rather than legal, hence unworthy of consideration, and that the Supreme Court's conception is legal rather than political, hence worthy of consideration. These claims would be mistaken, however. In the first place, the actual social practices which make Canadian political and legal institutions possible are not clearly demarcated as being either political or legal, so we cannot simply reject the ordinary Canadian's conception because it is "political rather than legal". Consider the Morgentaler case. ${ }^{57}$ Can we say that it was merely political or merely legal? Or is it obvious that a case which effectively decriminalizes abortion has both political and legal consequences, and affects both political and legal social practices? Brian Leiter's naturalistic

$57 R$ v. Morgentaler, Smoling and Scott (1986) 2 OR (2d) 353 (CA, affd [1988] 1 SCR 30 (SCC)). 
jurisprudence favours pedigree-criteria of law because criteria of that type are (supposedly) not vague themselves yet exclude vague and difficult-to-observe factors such as political ideology. But, as we noted, adherence to "the rule of law" is in some sense ideological, not to mention difficult to discern or observe in some instances, and is arbitrarily excluded by Leiter's concern for empirically falsifiable results. It is perhaps possible to offer an account of law on that basis, but it will be a very poor account when it comes to describing a legal right to vote in Canada. And it seems to me, at least, that a theory of law which precludes an adequate description of an actual legal right to vote is a poor theory of law.

Rather than "naturalizing" our problem, perhaps we can appeal to an epistemic authority of some type. On questions regarding the actual nature of a Canadian legal right, we might be tempted to grant greater epistemic authority to Canada's supreme court than to the average person on the street. But this theoretical strategy is also a poor one. The Court could, for instance, be mistaken. While we might hesitate to state that this is so with respect to the point in question, we cannot grant general epistemic authority to the Court simply because it is a supreme court. Perhaps the Court is the epistemic authority regarding particular points of Canadian law. While this may be so, that fact would not entail that it is an epistemic authority regarding law in general. If we assumed that it is, then we would not be developing an account of what law actually is, but rather an account of what the $\mathrm{Ca}-$ nadian Supreme Court says law is.

More importantly, the Court itself has expressed a conception of the franchise such that it (i) exists in virtue of being posited by law, (ii) lacks legal force, (iii) manifests considerable political force. Thus it seems at least possible that an illuminating account of a legal right requires more than giving an account of its strictly positive-law features. That would address (i), and perhaps (ii), but not (iii). Yet (iii) is important even though it is "political rather than legal". 
What lessons can we learn from the existence of a contradiction between participant-level conceptions of the Canadian legal right to vote? First, we can note that discerning at least some features of law may require reference to things other than readily observable characteristics, such as pedigreed legal statutes. Few legal theorists would disagree with this point, but we have seen that Leiter's attempt to break through legal-theoretical epistemic uncertainty regarding the concept of legal validity - that is, his attempt to support an exclusive account of the rule of recognition by means of appealing to its social-scientific utility - leads to an unwarranted emphasis on the practicalities of observation. We should not avoid difficult questions simply by choosing an easier route.

Secondly, and more generally, it is clear that a general, descriptive theory of law must have robust explanatory concepts. Those concepts must be able to describe and explain participant-level conceptions which contradict other participant-level conceptions. Moreover, these contradictions must be recognized for what they are. The Canadian right to vote is an example: we cannot discipline our explanatory concept by choosing between or unreservedly accepting either the Supreme Court's conception or the ordinary Canadian's conception. At the same time, however, we cannot simply impose our own conception in order to disregard the contradictions which seem to appear in our explanatory object. The perspectival features of a legal system ought to be explained rather than explained-away. 